\title{
Epithelium-specific deletion of TGF- $\beta$ receptor type II protects mice from bleomycin-induced pulmonary fibrosis
}

\author{
Min Li, ${ }^{1}$ Manda Sai Krishnaveni, ${ }^{2}$ Changgong Li, ${ }^{1}$ Beiyun Zhou, ${ }^{2}$ Yiming Xing, ${ }^{1}$ Agnes Banfalvi, ${ }^{2}$ \\ Aimin Li, ${ }^{1}$ Vincent Lombardi, ${ }^{3}$ Omid Akbari, ${ }^{3}$ Zea Borok,, ${ }^{2,4}$ and Parviz Minoo' \\ ${ }^{1}$ Division of Neonatology, Department of Pediatrics, ${ }^{2}$ Will Rogers Institute Pulmonary Research Center, Division of Pulmonary and Critical Care Medicine, \\ Department of Medicine, ${ }^{3}$ Department of Molecular Microbiology and Immunology, and 4Department of Biochemistry and Molecular Biology, \\ Keck School of Medicine, University of Southern California (USC), Los Angeles, California, USA.
}

\begin{abstract}
Idiopathic pulmonary fibrosis (IPF) is a chronic fibroproliferative pulmonary disorder for which there are currently no treatments. Although the etiology of IPF is unknown, dysregulated TGF- $\beta$ signaling has been implicated in its pathogenesis. Recent studies also suggest a central role for abnormal epithelial repair. In this study, we sought to elucidate the function of epithelial TGF- $\beta$ signaling via TGF- $\beta$ receptor II (T $\beta$ RII) and its contribution to fibrosis by generating mice in which $T \beta R I I$ was specifically inactivated in mouse lung epithelium. These mice, which are referred to herein as $T \beta R I^{N k x 2.1-c r e}$ mice, were used to determine the impact of $T \beta R I I$ inactivation on (a) embryonic lung morphogenesis in vivo; and (b) the epithelial cell response to TGF- $\beta$ signaling in vitro and in a bleomycin-induced, TGF- $\beta$-mediated mouse model of pulmonary fibrosis. Although postnatally viable with no discernible abnormalities in lung morphogenesis and epithelial cell differentiation, $T \beta R I I^{\text {Nkx2.1-cre }}$ mice developed emphysema, suggesting a requirement for epithelial T $\beta R I I$ in alveolar homeostasis. Absence of T $\beta$ RII increased phosphorylation of Smad2 and decreased, but did not entirely block, phosphorylation of Smad3 in response to endogenous/physiologic TGF- $\beta$. However, $T \beta R I I^{N k x 2.1-c r e}$ mice exhibited increased survival and resistance to bleomycin-induced pulmonary fibrosis. To our knowledge, these findings are the first to demonstrate a specific role for TGF- $\beta$ signaling in the lung epithelium in the pathogenesis of pulmonary fibrosis.
\end{abstract}

\section{Introduction}

Excess or dysregulated TGF- $\beta$ signaling is implicated in the pathogenesis of many diseases, including those of the lung. These range from adult pulmonary fibrosis to the neonatal chronic lung disease bronchopulmonary dysplasia (1). Idiopathic pulmonary fibrosis/usual interstitial pneumonia (IPF/UIP) is a fibroproliferative disorder of unknown etiology characterized by progressive ECM deposition and remodeling by $\alpha$-SMA-expressing myofibroblasts. Fibroblast accumulation progressively results in excessive scarring and changes in lung architecture leading to loss of lung function and death. Short of lung transplantation, there are currently no effective treatments for IPF. Although initially thought to result from mesodermal defects in repair following injury or viral infection, a new perspective on the pathogenesis of IPF includes a role for the lung epithelium (2-4). In this paradigm, epithelial injury, through release of profibrotic mediators, is believed to set up a cascade of aberrant epithelial-fibroblast crosstalk reminiscent of abnormal wound healing (5). Embedded in the notion of a role for epithelium in the pathogenesis of IPF is the possibility that, in addition to arising from resident lung fibroblasts, fibroblasts within fibrotic foci in IPF lungs could be derived from epithelial cells via the process of epithelial-mesenchymal transition, known as $\operatorname{EMT}(6,7)$. The mechanism and the extent to which this pathway contributes to IPF remain unknown, as are the inciting factors

Authorship note: Min Li and Manda Sai Krishnaveni contributed equally to this work. Zea Borok and Parviz Minoo contributed equally to this work.

Conflict of interest: The authors have declared that no conflict of interest exists. Citation for this article: J Clin Invest. 2011;121(1):277-287. doi:10.1172/JCI42090 that lead to epithelial injury. One incontrovertible aspect of IPF pathogenesis is the involvement of dysregulated TGF- $\beta$ signaling.

TGF- $\beta$ ligands comprise a large family of structurally related growth and differentiation signaling factors (8). Given both the specificity and versatility of its functions, the core of the TGF- $\beta$ signal transduction pathway appears surprisingly simple. TGF- $\beta$ functions by interacting with a heteromeric complex of transmembrane serine/threonine kinase receptors, the type I (T $\beta R I)$ and the type II (T $\beta$ RII) receptors. Stimulation by either activin or TGF- $\beta$ leads to phosphorylation of transcription factors Smad2 and/or Smad3, which in turn associate and form a complex with Smad4 $(8,9)$. This heteromeric complex translocates to the nucleus, where transcription of target genes is modulated via direct DNA binding or through interaction with promoterspecific transcription factors (10).

Critical roles for TGF- $\beta$ signaling have been found in both normal development and disease. For example, Tgfb2-null mice die perinatally, with developmental abnormalities in many organs including limbs, heart, and lungs (11). Tgfb3 mutants also die perinatally due to lung dysplasia and cleft palate (12). Conventional deletion of Smad 2 causes embryonic lethality, whereas $\operatorname{Smad3}^{-/-}$mice are born alive. The latter mice develop a pulmonary phenotype consistent with progressive emphysema (13). Targeted deletion of Smad4 also causes a wide range of developmental abnormalities including defective prechordal plate, node, and notochord (14). Finally, conventional deletion of both T $\beta$ RI (Alk5) and T $\beta$ RII causes early embryonic lethality, indicating their critical role in early embryogenesis, but precluding further investigation of their functions in later development and in adults (15). 


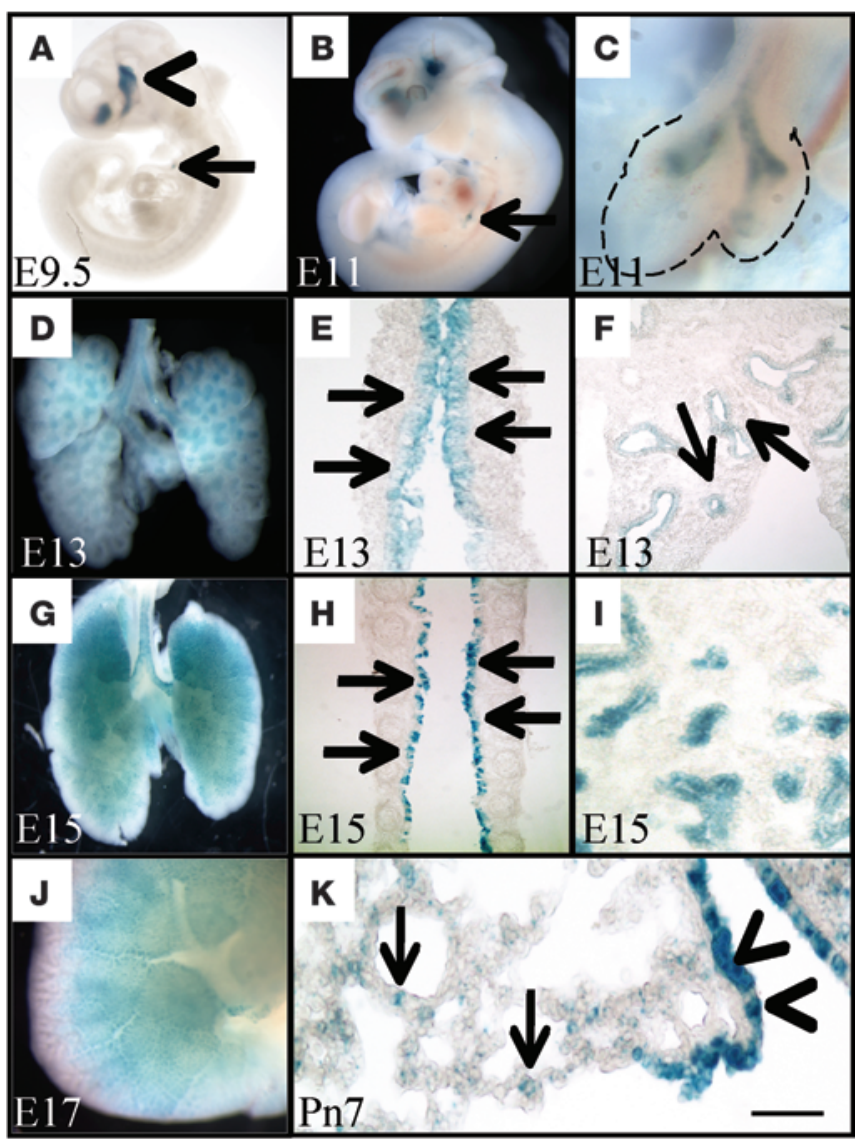

In animal models that are thought to mimic the process of human IPF, genetic approaches have identified specific components of the TGF- $\beta$ pathway that may participate in lung fibrosis. For example, Smad3 $3^{-/-}$mice exhibit relative resistance to bleomycin-induced pulmonary fibrosis (13). However, TGF- $\beta$ signaling within the lung is confounded by the complexity of the highly specialized cell types and their specific responses to TGF- $\beta$. Components of the TGF- $\beta$ pathway including Smads and the transmembrane receptors are expressed in both endodermal and mesodermal cell derivatives, or "compartments," of the lung. The extent to which TGF- $\beta$ receptors within each compartment contribute to the specificity and versatility of signaling during embryonic and postnatal development remains unknown. Similarly, respective mesodermal or endodermal contribution of signaling through each of the TGF- $\beta$ receptors to pulmonary fibrosis remains entirely unknown. In the current study, we used the endoderm-specific $N k \times 2.1$-cre approach to inactivate T $\beta$ RII specifically within the lung epithelial compartment. Surprisingly, epithelium-specific deletion of T $\beta R I I$ caused no discernible abnormalities during embryonic lung development. However, absence of epithelial T $\beta$ RII activity in postnatal life was associated with nonprogressive emphysema. As inactivation of T $\beta$ RII did not cause lethality, we were also presented with an opportunity to examine the role of endodermal T $\beta$ RII in lung injury using a murine model of bleomycininduced pulmonary fibrosis. Importantly, endodermal loss of $\mathrm{T} \beta \mathrm{RII}$ conferred partial protection against bleomycin-induced fibrosis, implying a central role for alveolar epithelium in

\section{Figure 1}

Epithelial specificity of recombination induced by $N k \times 2.1$-cre in organs of double-transgenic Nkx2.1-cre;Rosa26R mice. LacZ staining was observed in the brain (arrowheads) and thyroid primordium (arrows) in E9.5 embryos (A). Nkx2.1-cre-mediated recombination in the lung was first visible in E11 lungs (arrow in B and outlined in C). In E13, E15, and E17 embryonic lungs, LacZ staining was restricted to epithelial cells in the lung ( $\mathbf{D}, \mathbf{F}, \mathbf{G}, \mathbf{I}$, and $\mathbf{J})$, but was also expressed in the tracheal epithelium (E and $\mathbf{H})$. In Pn7 neonates (K), LacZ staining was localized to the bronchoalveolar duct junction (arrowheads) and alveolar type II cell progenitors (arrows). Scale bar: $2 \mathrm{~mm}$ (B and $\mathbf{G}$ ); $800 \mu \mathrm{m}$ (A and D); $400 \mu \mathrm{m}$ (H and J); $200 \mu \mathrm{m}$ (E); $100 \mu \mathrm{m}$ (F, I, and K); and $40 \mu \mathrm{m}(\mathbf{C})$.

development of fibrosis. To our knowledge, this is the first direct demonstration of a specific role for the lung endoderm-specific TGF- $\beta$ signaling pathway in the pathogenesis of pulmonary fibrosis.

\section{Results}

Epithelial inactivation of T $\beta R I I$ by Nkx2.1-cre-driven recombination. Previous studies have shown that conventional deletion of T $\beta$ RII leads to early embryonic lethality (11), while mesenchymal deletion of T $\beta$ RII results in gross abnormalities of trachea and lung (16). To study the role of T $\beta$ RII specifically in lung epithelial cells, we crossed $T \beta R I I^{l / f l}$ females with $N k x 2.1$-cre male mice and backcrossed the heterozygotes to generate $T \beta R I^{f / f f} ; N k \times 2.1$-cre (simply, $\left.T \beta R I I^{N k x 2.1-c r e}\right)$ progeny. Nkx2.1 encodes a key transcriptional regulator of lung morphogenesis whose onset of expression in the mouse occurs on day E9.5. The Nkx2.1-cre mouse line carries a BAC gene in which the sequences encoding the cre recombinase are inserted within the first $15 \mathrm{bp}$ of $N k \times 2.1$ exon 2 (17). In Nkx2.1-cre;ROSA26$\mathrm{LacZ}$ double-transgenic embryos, LacZ staining can be detected in the primordium of the lung in E11 mouse embryos (Figure 1, B and C). This staining is limited to the endodermally derived epithelial progenitor cells forming the primitive airways and the first branched structures of the embryonic lung (Figure 1). Thereafter, LacZ can be found in all endodermally derived epithelial cells throughout lung development (18). In postnatal lung samples, LacZ staining is found in the epithelium of the bronchoalveolar duct junction (arrowheads in Figure $1 \mathrm{~K}$ ) as well as alveolar epithelial type II cells (arrows in Figure 1K).

$T \beta R I I^{N k x 2.1-c r e}$ mice were postnatally viable and fertile. Regular mating consistently produced progeny at expected Mendelian ratios. Nkx2.1-cre-induced lung deletion of T $\beta R I I$ exon 2 was validated by PCR analysis of genomic DNA from lung and other organs (control) of transgenic mice. A PCR product that indicated deletion of exon 2 was amplified from DNA extracted from $T \beta R I^{N k x 2.1-c r e}$ lungs, but not from DNA obtained from other tissues, including the heart, where $N k \times 2.1$ is not expressed (Figure 2B).

$\mathrm{T} \beta \mathrm{RII}$ protein was examined by immunohistochemistry in $T \beta R I^{f / / f l}$ and $T \beta R I I^{N k \times 2.1-c r e}$ lungs. Immunostaining was found primarily in cells that appeared to have characteristics of alveolar type II cells in the lungs of control T $\beta R I^{f l / f l}$ mice (Figure 2C). In contrast, little to no detectable immunoreactivity for T $\beta$ RII was present in $T \beta R I I^{N k \times 2.1-c r e}$ lungs (Figure 2D). Western blot analysis was used to measure steady-state levels of T $\beta$ RII protein and those of downstream targets of TGF- $\beta$ signaling in mutant and control lungs. In total lung, the level of T $\beta$ RII was reduced by approximately $70 \%$ compared with controls (Figure 2, E and F). Levels of total and phosphorylated Smad2 (p-Smad2) and p-Smad3, as well as p-ERK 
A

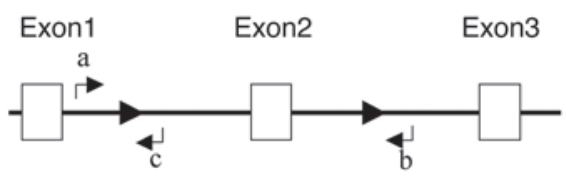

B

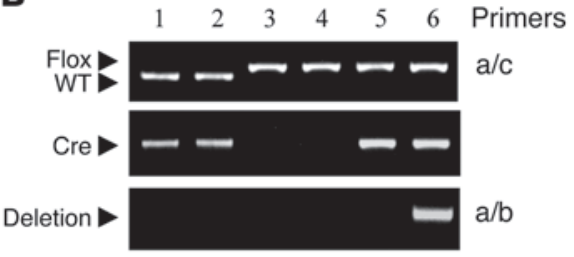

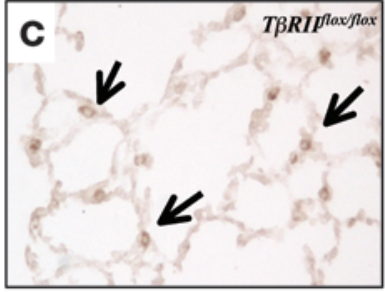

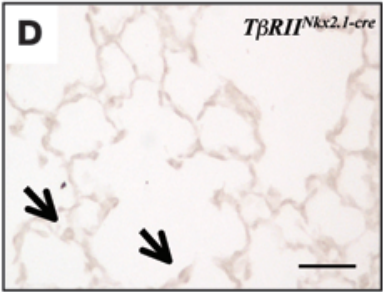

E

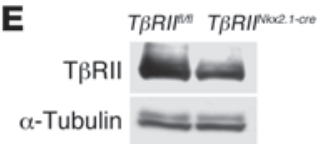

$\mathbf{F}$

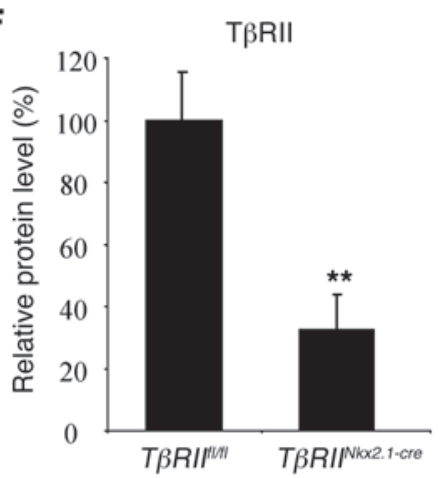

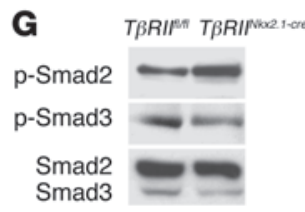

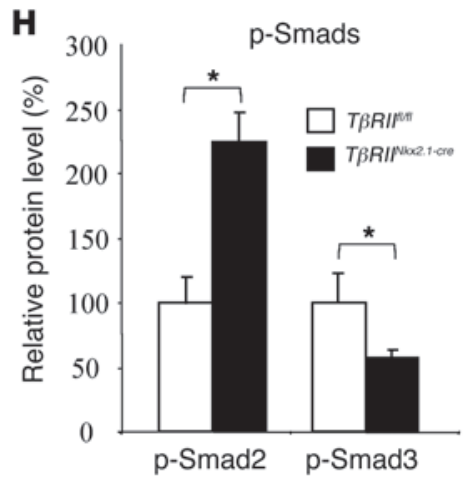

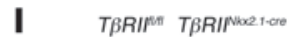

p-Erk $=$

Erk $=$

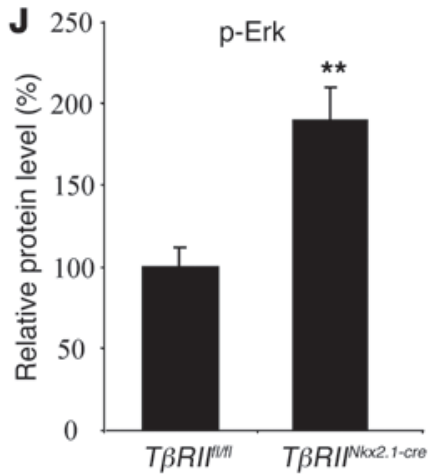

Figure 2

Generation and validation of $T \beta R / /$ conditional knockout alleles. (A) Schematic map of the mouse $T \beta R / /$ floxed locus. Arrowheads designate loxP sequences. Primers a, b and c, used in genotyping the mice, are also shown. (B) PCR genotyping using the 3 primers in A. Heart (lanes 1, 3 , and 5) and lung tissue (lanes 2, 4, and 6) from floxed alleles and wild-type alleles can be distinguished by their size using primers a and b. Primers for Cre detection are provided in Methods. Deleted $T \beta R / I$ allele is detected using primers a and $b$. (C and $\mathbf{D})$ Immunohistochemical analysis

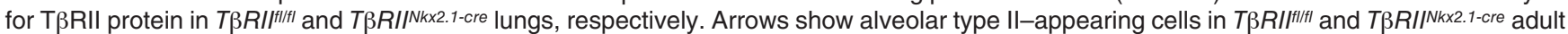
lungs. (E and F) Western blot analysis and densitometric quantification of total protein homogenates from $T \beta R / I^{f / / f l}$ (control) and $T \beta R / I^{N k \times 2.1-c r e ~}$ (mutant) lungs, respectively. Values were normalized against $\alpha$-tubulin. (G) p-Smad2 and p-Smad3, normalized against total Smad2 and Smad3, respectively. (H) Densitometric quantification of the Western blot in $\mathbf{G}$. (I and $\mathbf{J}$ ) p-ERK normalized against total ERK and densitometric quantification. ${ }^{*} P<0.01 ;{ }^{\star} P<0.05 . n=3$. Scale bar: $40 \mu \mathrm{m}$.

were also measured. Compared with controls, total Smad2 protein remained unchanged in the mutant lungs (Figure 2, G and $\mathrm{H}$ ). However, Smad 3 and its activated form ( $\mathrm{p}$-Smad3) were both decreased, whereas $\mathrm{p}$-Smad2 was increased in T $\beta R I I^{N k x 2.1-c r e}$ lungs (Figure 2). In addition, there was increased activation of ERK in the TRRII $I^{N k 2.1-c r e}$ lungs compared with $T \beta R I I^{f / f l}$ controls (Figure 2, I and J).

We also examined the TGF- $\beta$ pathway and its response to recombinant TGF- $\beta$ treatment in isolated type II cells (Figure 3 ). Western blot analysis of total proteins from $T \beta R I I^{\text {Nkx2.1-cre }}$ type II cells showed more than $70 \%$ reduction in the abundance of T $\beta$ RII protein, when compared with T $\beta R I I^{f l} f f$ type II cells (Figure 3, A and B). In contrast to total lung (as shown in Figure 2), the abundance of Smad2 or Smad3 proteins was not discernibly changed, with or without treatment with recombinant TGF- $\beta$ (Figure 3, C and D). However, phosphorylated Smad2 was reduced in untreated $T \beta R I I^{N k \times 2.1-c r e}$ alveolar type II cells, whereas phosphorylated Smad3 was only faintly detectable on the Western blot in either mutant or control type II cells. Treatment with TGF- $\beta$ increased both phosphorylated Smad2 and Smad3 in the mutant type II cells, but compared with the controls, the response, particularly for $\mathrm{p}$-Smad3, was blunted (Figure 3, C and D). Overall, the basal level of p-ERK and its response to TGF- $\beta$ appeared to be equal in T $\beta R I I^{N k x 2.1-c r e}$ and $T \beta R I I^{f l} / f l$ type II cells (Figure 3, E and F). 
A
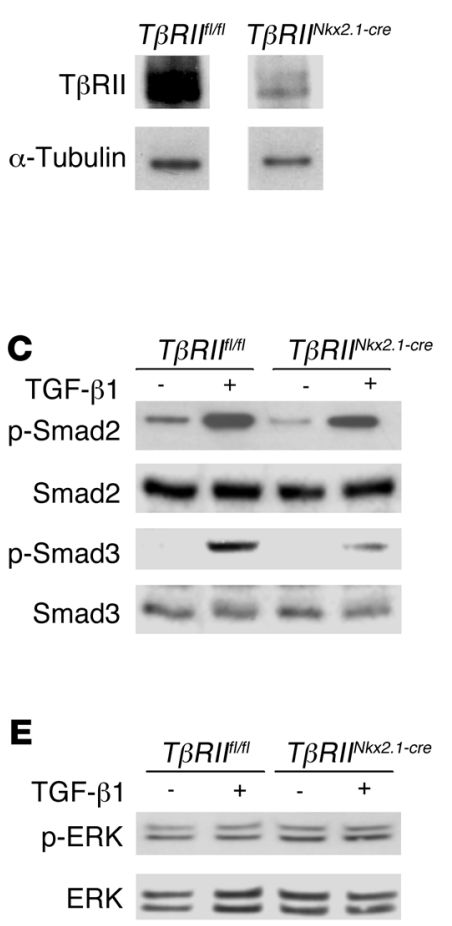
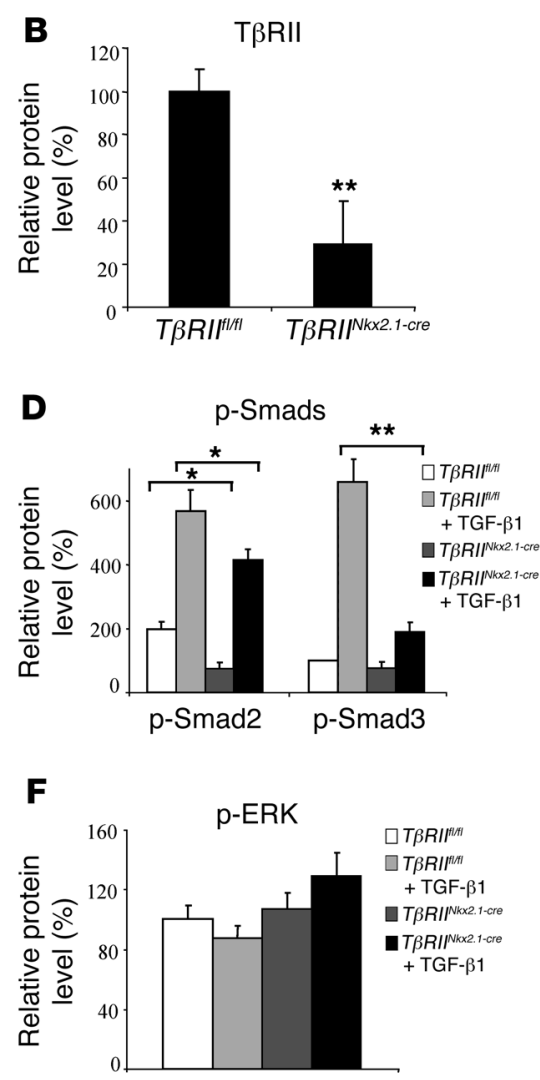

Figure 3

Characterization of the TGF- $\beta$ pathway in isolated alveolar epithelial type II cells. (A) T $\beta$ RII levels determined by Western blot analysis in $T \beta R / I^{f / l / f l}$ and $T \beta R / I^{N k \times 2.1-c r e}$ type II cells. (C) Western blot analysis of Smads and $p$-Smads in control and TGF- $\beta$-treated type II cells. (E) Western blot analysis of ERK and $p$-ERK in control and TGF- $\beta$-treated type II cells. Quantification of $\mathbf{A}, \mathbf{C}$, and $\mathbf{E}$ is shown in $\mathbf{B}, \mathbf{D}$, and $\mathbf{F}$, respectively. ${ }^{\star} P<0.01 ;{ }^{\star} P<0.05$.

As we observed in vivo changes in the components of the TGF- $\beta$ signal transduction pathway, particularly in Smad2 and Smad3, described above, it became logical to examine the impact of epithelium-specific T $\beta$ RII deletion on select known targets of TGF- $\beta$. Surprisingly, real-time PCR analysis revealed a complex and mixed response of TGF- $\beta$ target genes, which encode components of the ECM. Thus, fibronectin 1 and collagen $3 \mathrm{a} 1$ were significantly increased in mutant lungs. In contrast, collagen 1a1 (Col1a1), Col4a1, and $\alpha$-SMA remained unchanged (Figure 4H). Potential alterations in expression of metalloproteinases and their tissue inhibitors were also interrogated. Although expression of connective tissue growth factor (Ctgf), plasminogen activator inhibitor-1 (Pai1), $M m p 2, M m p 9$, and tissue inhibitor of metalloproteinase 2 (Timp2) was unchanged, transcripts for Mmp12 and Timp1 were increased several fold (Figure 4I).

$T \beta R I I^{N k x 2.1-c r e ~ m i c e ~ e x h i b i t ~ r e l a t i v e ~ r e s i s t a n c e ~ t o ~ b l e o m y c i n-~}$ induced lung injury. Adenoviral overexpression of TGF- $\beta$ induces pulmonary fibrosis (19). Additionally, TGF- $\beta$ is

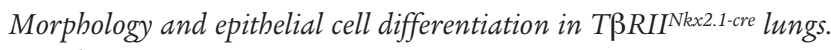
$T \beta R I I^{N k x 2.1-c r e}$ mice survive and reproduce normally. When compared with either $T \beta R I I^{f l / f l}$ or wild type age-matched mice, gross

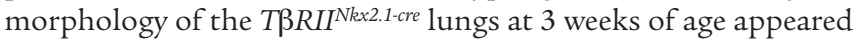
normal. Remarkably, after 8 weeks of life, distinct signs of alveolar enlargement, a phenotype consistent with emerging emphysema, was discerned in the lungs of T $\beta R I I^{N k x 2.1-c r e}$ mice (Figure 4, A-D). Quantification of alveolar diameter by several methods including mean liner intercept and direct distal alveolar counts supported the occurrence of emphysema in 8-week-old T $\beta R I I^{N k x 2.1-c r e}$ mice (Figure 4, E-G). However, later examination of the mutant lungs in 11-month-old mice revealed no sign of progression of this phenotype (data not shown).

Lung epithelial cell differentiation was examined by immunofluorescence using antibodies to cell-specific markers. Distribution of $\mathrm{Nkx} 2.1$ and surfactant protein $\mathrm{B}(\mathrm{Sp}-\mathrm{B})$, a marker of both airway and alveolar epithelial cells, was comparable in mutant and control lungs (Supplemental Figure 1, C-F; supplemental material available online with this article; doi:10.1172/JCI42090DS1). Immunostaining with an anti-CC-10 antibody showed normal differentiation and spatial distribution of Clara cells in both mutant and control lungs (Supplemental Figure 1, C and D). $\alpha$-Tubulin, a marker of ciliated cells, was also found to be normally expressed on the apical side of the proximal epithelial cells in mutant and control mice (Figure 1, A and B). The magnitude and distribution of Sp-C and T1- $\alpha$, markers respectively of type II and type I cells, were also unchanged, indicating preservation of number and distribution of specialized alveolar epithelial cell types in $T \beta R I I^{\text {Nkx2.1-cre }}$ lungs. Thus, lung epithelial cell differentiation does not appear to be dependent on epithelial T $\beta$ RII signaling. a key mediator of EMT, a process by which epithelial cells may contribute to pulmonary fibrosis (20). Epithelium-specific deletion of T $\beta R I I$ and the postnatal viability of mutant mice presented a unique opportunity to examine what role, if any, TGF- $\beta$ signaling, specifically via epithelial T $\beta$ RII, may have in a murine model of pulmonary fibrosis. Bleomycin was administered at $2 \mathrm{U} / \mathrm{kg}$ intratracheally (i.t.)

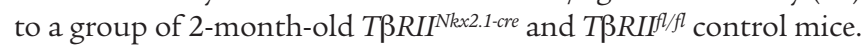
Intratracheal administration of bleomycin caused lethality in $75 \%$ of control mice by day 16 . Remarkably, all mutant mice survived the treatment (Figure 5A). Because of this differential survival rate, we next examined the impact of intranasal (i.n.) administration of bleomycin. This mode of delivery caused less severe injury and allowed survival of control mice and hence their analysis. Following i.n. administration of bleomycin, weight loss, a normal occurrence following bleomycin exposure, was monitored at regular intervals. Initially, weight loss was similar in the 2 groups. Within the first 5 days, however, while $T \beta R I I^{N k x 2.1-c r e}$ mice began to recover, $T \beta R I^{f / f l}$ control mice continued to lose weight. Between day 2 and day 13 of the study, there was a significant difference between the 2 groups of mice, with more rapid stabilization of weight for $T \beta R I I^{N k x 2.1-c r e}$ mice. By day 13, the $T \beta R I I^{f / f l}$ mice in the control group had recovered to the level of the mutant mice (Figure 5B).

On day 14 following i.t. bleomycin administration $(1.3 \mathrm{U} / \mathrm{kg})$, we obtained total lung lavage and measured protein concentration to determine the extent of injury and epithelial permeability. We found significantly lower permeability in the TRRII $I^{N k x 2.1-c r e}$ lungs when compared with $T \beta R I I^{f / f l}$ lungs (Figure 5D). Consistent with the latter results, measurement of lung compliance after 14 days of exposure to bleomycin also showed significant differences between $T \beta R I I^{N k x 2.1-c r e}$ and T $\beta R I I^{f / f l}$ control mice (Figure 5C). 

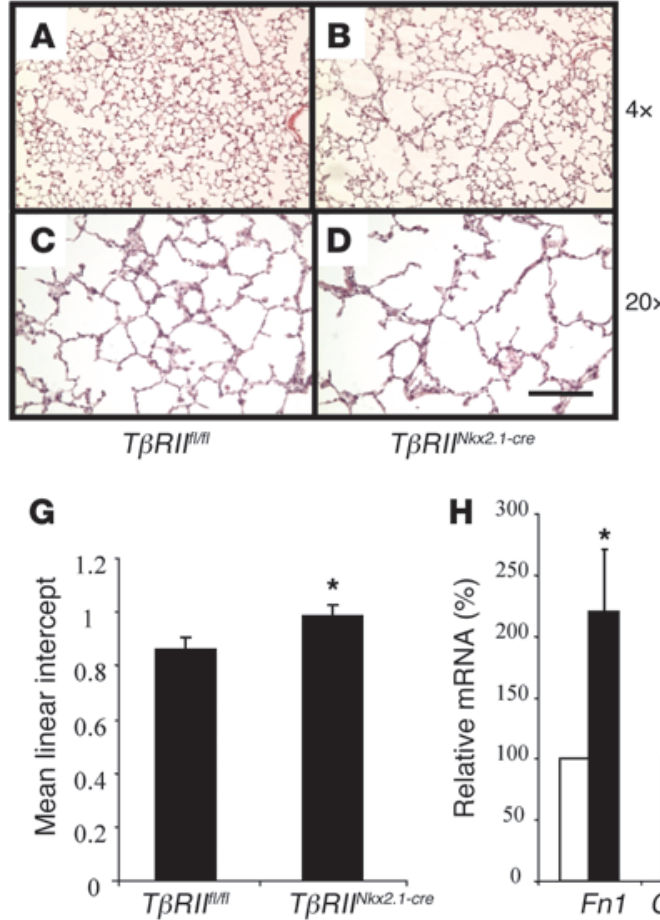

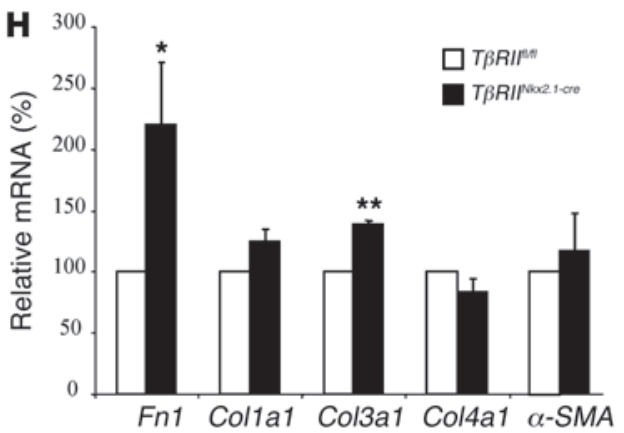

E

口TBRIM

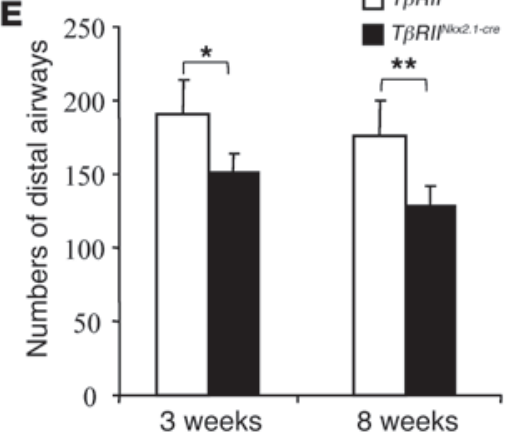

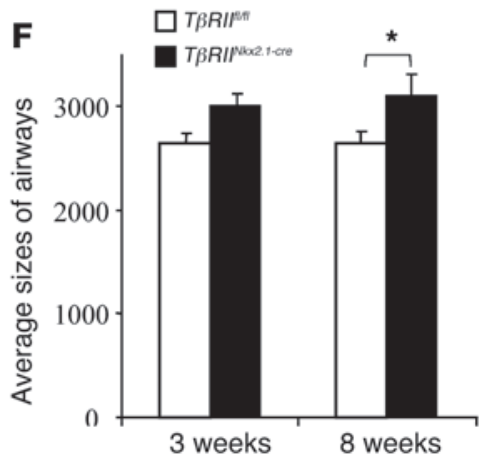

Figure 4

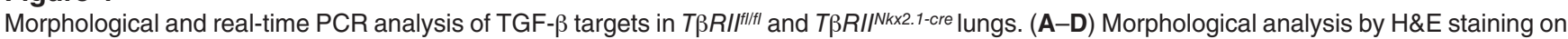
sections of 8-week-old lungs showing the presence of alveolar enlargement. (E) Distal airway counts in multiple sections of control and mutant lungs at both 3 weeks and 8 weeks of age. (F) Quantification of average size in pixels of airways using Image J. (G) Mean linear intercept measurements $(1.0=200 \mu \mathrm{m}) . n=3$ per group; $5-10$ slides from each group. (H) Real-time PCR analysis of ECM components. (I) Real-time PCR analysis of TGF- $\beta$ targets. $n=3$ per group; ${ }^{* *} P<0.01 ;{ }^{*} P<0.05$. Scale bar: $200 \mu \mathrm{m}$.

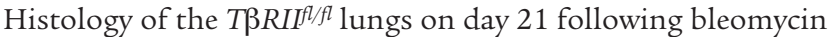
administration showed extensive, focalized, and heterogeneous dense interstitial fibrosis in paraseptal regions (Figure 6A). In contrast, only a few small and isolated fibrotic foci were observed in the T $\beta R I I^{\text {Nkx2.1-cre }}$ lungs (Figure 6B). Deposition of collagen, a key feature in bleomycin-induced pulmonary fibrosis, was assessed by two different methods. First the amount of collagen deposited was examined by trichrome staining after 21 days of injury (Fig- ures 6, C and D). Second, soluble collagen content was measured in total lung homogenates at 14 days after injury $(1.3 \mathrm{U} / \mathrm{kg})$. As shown in Figure 6E, compared with saline controls, the mutant lungs showed less collagen deposition in response to bleomycin by Sircol assay when compared with $T \beta R I I^{f / f l}$ controls.

In addition, analysis of apoptosis within the fibrotic foci by TUNEL staining revealed a significant difference between $T \beta R I I^{N k x 2.1-c r e}$ and $T \beta R I I^{f l / f l}$ lungs. There was nearly a 3-fold increase
A

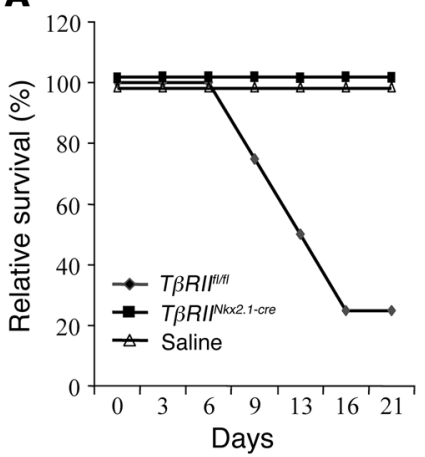

B

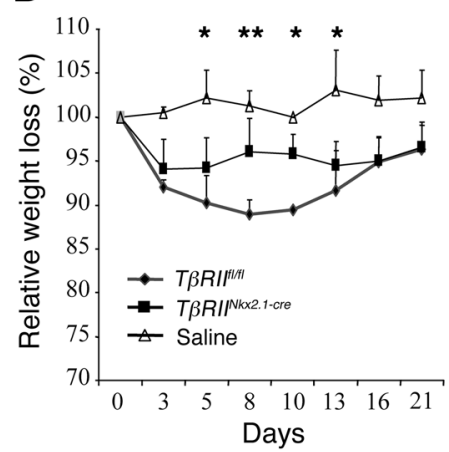

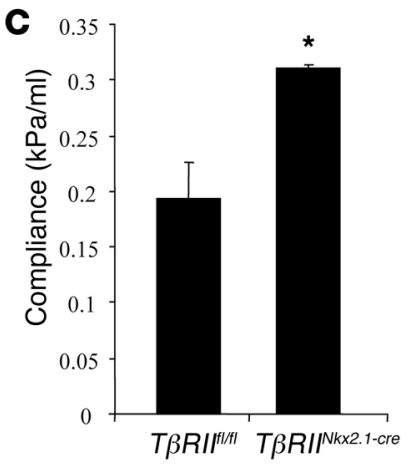

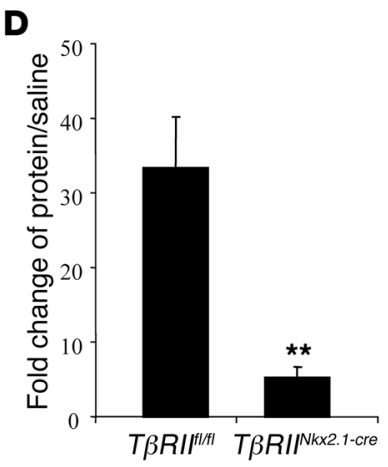

Figure 5

Physiological impact of bleomycin injury in $T \beta R / I^{f / f l}$ and $T \beta R / I^{N k x 2.1-c r e}$ mice. (A) Survival profile of mice receiving i.t. injection of bleomycin or saline (control). (B) Weight loss in mice receiving i.n. instillation of bleomycin or saline (control). Animals were monitored up to 21 days. (C) Compliance $(\mathrm{kPa} / \mathrm{ml})$ in control and mutant lungs on day 14 of bleomycin treatment. (D) Epithelial permeability on day 14 after bleomycin exposure as measured by protein content of BAL. ${ }^{* *} P<0.01 ;{ }^{*} P<0.05 . n=5$ per group. 

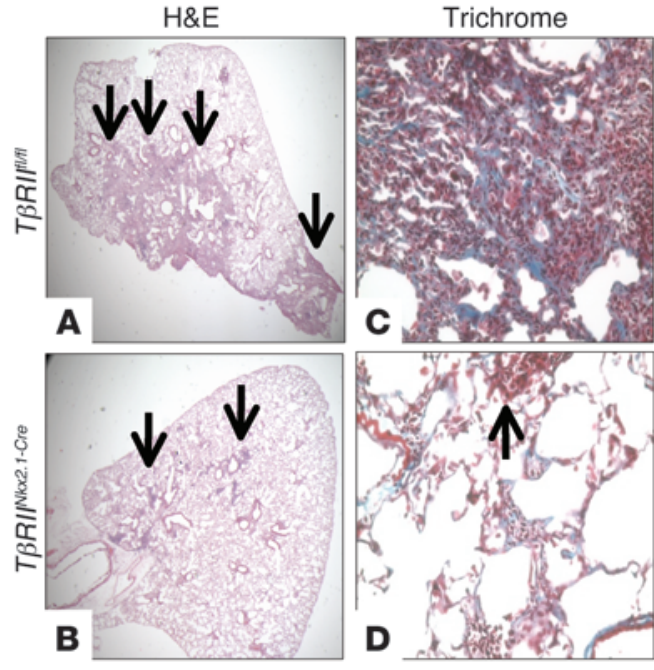

$\mathbf{E}$

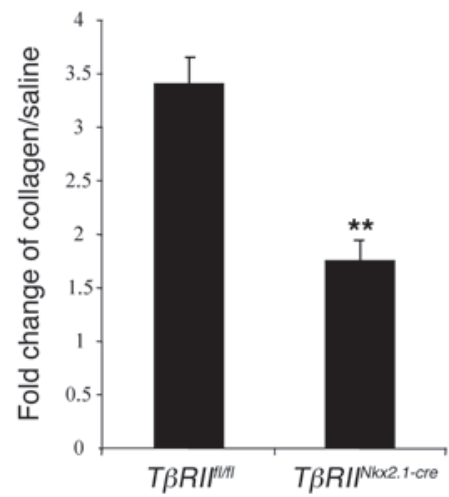

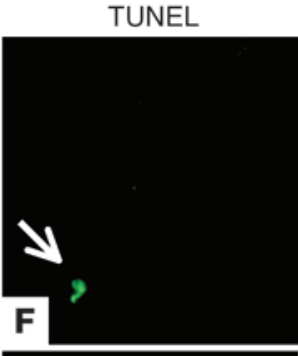
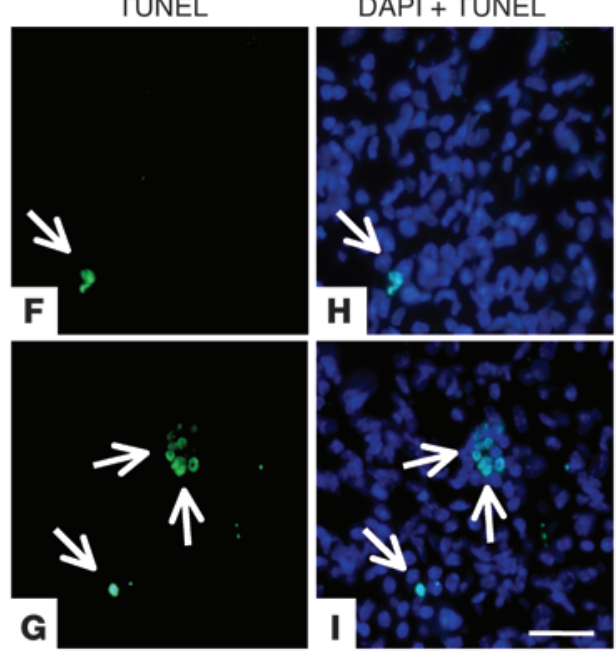

$\mathbf{J}$

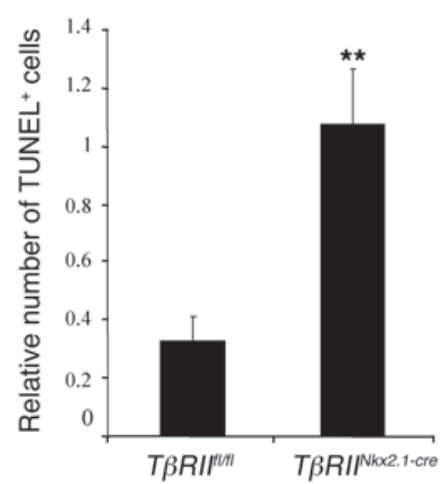

\section{Figure 6}

Relative resistance to bleomycininduced fibrosis in $T \beta R / I^{N k \times 2.1-c r e}$ mice. Representative lung histology on day 21 after exposure to bleomycin in $T \beta R / I^{f / f f l}(\mathbf{A})$ and $T \beta R / I^{N k \times 2.1-c r e}$ (B) mice. Trichrome staining on sections of the same lungs are shown in $\mathbf{C}$ and $\mathbf{D}$, respectively. Quantification of collagen in the lungs by Sircol assay (E); ${ }^{* *} P<0.005$. TUNEL assays are shown in $\mathbf{F}$ and $\mathbf{H}$ for $T \beta R I^{f|l| f \mid}$ and $\mathbf{G}$ and I for $T \beta R / I^{N k \times 2.1-c r e ~ l u n g s . ~}$ $\mathbf{H}$ and $\mathbf{I}$ are with DAPI. (J) Quantification of positive (green) cells in the fibrotic foci of $T \beta R / I^{f / f f}$ and $T \beta R / I^{N k \times 2.1-c r e}$ lungs. Scale bar: 2 $\mathrm{mm}$ (A and $\mathbf{B}) ; 200 \mu \mathrm{m}$ (C and $\mathbf{D})$; $50 \mu \mathrm{m}(\mathbf{F}-\mathbf{I}) .{ }^{* \star} P<0.01 ; n=3-6$ slides from each lung. in TUNEL-positive cells in the mutant fibrotic foci compared with those in the control lungs (Figure 6, F-J). Further studies showed that the apoptotic cells were nearly exclusively positive for vimentin (data not shown). Whether EMT contributes to this cell population remains unknown, as such information awaits development of additional mouse lines with cell lineage-tracing capabilities.

Attenuated response to bleomycin in T $\beta R I I^{N k x 2.1-c r e ~ l u n g s . ~ F i b r o-~}$ blast-specific protein 1 (FSP1) and $\alpha$-SMA are increased in both IPF and bleomycin-induced pulmonary fibrosis $(21,22)$. Using immunohistochemistry and Western blot analysis, protein levels for $\alpha$-SMA and FSP1 were examined in mutant and control lungs (Figure 7, A-F). Based on Western blot results normalized to lamin A/C, both FSP1 and $\alpha$-SMA were significantly reduced by nearly one-half in the mutant lungs, compared with $T \beta R I I^{\ell / f l}$ controls. To assess the impact of bleomycin treatment, we also measured by real-time PCR the mRNA level for $\alpha$-SMA and a number of profibrotic mediators that included fibronectin and collagens. Compared with controls, fibronectin and $\alpha$-SMA mRNA levels were markedly reduced in the mutant lungs (Figure $7 G$ ). Real-time PCR quantification of mRNA measurement was also applied for Mmps and their tissue inhibitors (Timps) and the TGF- $\beta$ targets Pail and Ctgf, as they are known to contribute to development of pulmonary fibrosis $(23,24)$. Relative expression of mRNA for each gene in the injured lungs, normalized to the value found in uninjured lungs, for mutant and control mice are plotted and shown in Figure 7H. Whereas changes in Ctgf and
Pai1 were negligible, $M m p 2, M m p 12$, and Timp1 were significantly lower and Timp2 was higher in the mutant mouse lungs versus the controls. In addition, a similar pattern of $M m p 12$ response was observed in lung macrophages (data not shown).

While the bleomycin injury model allowed an indirect approach to examine the impact of epithelium-specific T $\beta$ RII deletion on the response of the lung tissue to TGF- $\beta$-mediated injury, we also examined the response of isolated alveolar type II cells to direct stimulation by recombinant TGF- $\beta$. Consistent with the observation in total lungs, Ctgf, Pai1, Mmp12, and Timp1 values, compared with controls were greater in the T $\beta R I I^{N k x 2.1-c r e}$ alveolar type II cells, with the latter two reaching statistical significance (Figure 8A, asterisks). With TGF- $\beta$ treatment, Ctgf and Pail mRNAs increased more than 2 -fold in T $\beta R I^{\prime l / f l}$ type II cells. In contrast, Ctgf and Pai1 mRNAs in $T \beta R I I^{N k x 2.1-c r e}$ cells were unresponsive to TGF- $\beta$ treatment. After 1 hour of TGF- $\beta$ treatment, $M m p s$ and Timps slightly increased in the control cells (values above unity). Remarkably, similar treatment with TGF- $\beta$ resulted in decreased mRNA for Mmp12 and Timp1 in isolated T $\beta R I I^{N k x 2.1-c r e}$ alveolar type II cells (Figure 8B).

\section{Discussion}

The goal of the present study was to define the precise role of epithelial T $\beta$ RII signaling in lung development and disease. In the lung, the role of specific receptors is complicated by the heterogeneity of cell types thought to exceed 40 varieties derived from both the embryonic endoderm and mesoderm. Using the 

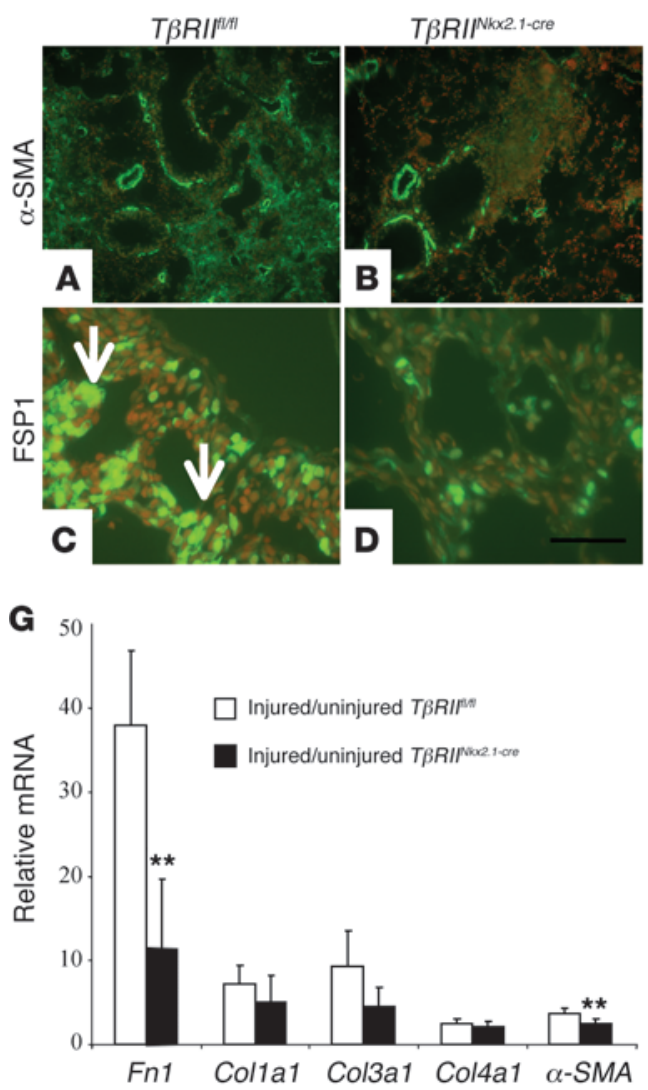

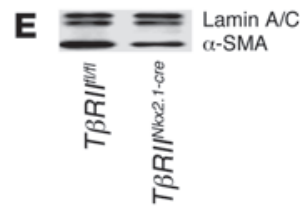

$\mathbf{F}$

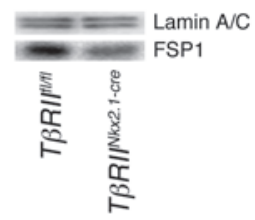

H

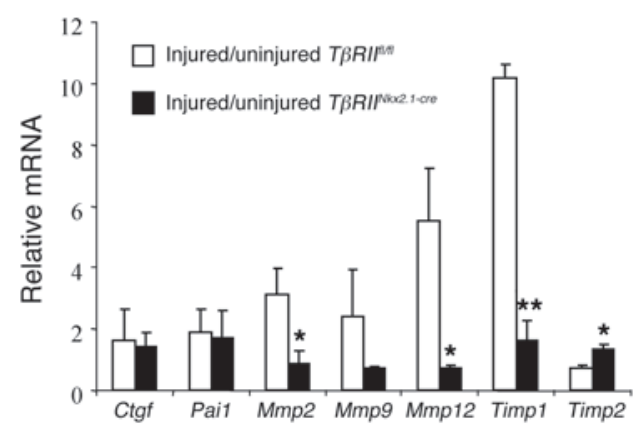

\section{Figure 7}

Characterization of the fibrogenic markers and TGF- $\beta$ targets in $T \beta R / I^{f / f l}$ and $T \beta R / I^{N k \times 2.1-c r e}$ lungs exposed to bleomycin. Immunofluorescence for $\alpha$-SMA in $T \beta R I^{f / f f I}(\mathbf{A})$ and $T \beta R / / N k \times 2.1$-cre lungs (B) on day 21 after bleomycin injury. (C and D) Immunofluorescence analysis for FSP1 in control and mutant lungs. ( $E$ and $F$ ) Western blot analysis of $\alpha$-SMA and FSP1 normalized to lamin $A / C$ in control and mutant lungs. Fold increase in mRNAs (injured/ uninjured ratio) for ECM components (G) and Ctgf, Pai1, metalloproteinases, and their inhibitors (H) by qPCR. $n=3$ per group. ${ }^{\star \star} P<0.05 ;{ }^{\star} P<0.01$. Scale bar: $100 \mu \mathrm{m}$. endoderm-specific Nkx2.1-cre, we deleted exon 2 of T $\beta R I I$ specifically in lung epithelial progenitors. Surprisingly, epithelial inactivation of T $\beta R I I$ exon 2 did not alter the course of embryonic lung development as $T \beta R I I^{N k x 2.1-c r e}$ mutant pups were born alive and showed no signs of respiratory distress. Interestingly, however, after 8 weeks of life, T $\beta R I I^{N k x 2.1-c r e}$ lungs exhibited distinct but mild signs of airspace enlargement associated with reduced phosphorylation of Smad3 (Figure 2). Mice carrying a null Smad3 allele also develop alveolar instability manifested as emphysema/alveolar enlargement (13). In Smad3 $3^{-/-}$mice, steady-state mRNA for the metalloproteinase $M m p 12$, known to be negatively regulated by TGF- $\beta$, was significantly increased (13). Similarly, Mmp12 mRNA was significantly increased in T $\beta R I I^{\text {Nkx2.1-cre }}$ mutant lungs in association with decreased p-Smad3 (Figure 4). Parallel changes in MMP-12 and P-Smad3 were also found in isolated $T \beta R I I^{N k x 2.1-c r e}$ type II cells, suggesting that the observed phenotype was the direct result of alterations within the epithelium and downstream of T $\beta$ RII. MMP-12 is considered an etiologic mediator of emphysema (25). Targeted deletion of Mmp12 alone protects from cigarette smoke-induced emphysema (26), while in a porcine model, an Mmp-9/12 inhibitor substantially ameliorates morphological emphysema (27). The results of the current

\section{Figure 8}

Quantitative analysis of mRNA expression of TGF- $\beta$ targets in isolated $T \beta R I^{f \mid l f l}$ and $T \beta R / I^{N k \times 2.1-c r e}$ alveolar type II (AT2) cells. (A) Real-time

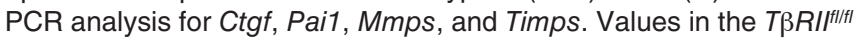
type II cells were adjusted to unity and compared with values obtained in $T \beta R / I^{N k \times 2.1-\text { cre }}$ cells. (B) Response (fold induction) of the same genes as in $\mathbf{A}$ to TGF- $\beta$ treatment of type II cells. ${ }^{* *} P<0.05$; ${ }^{*} P<0.01$. study establish a functional link between T $\beta$ RII, Smad3 activation, and regulation of Mmp-12 in the maintenance of alveolar stability, a finding with potential therapeutic implications.

Unexpectedly, epithelium-specific inactivation of $T \beta R I I$ caused hyperphosphorylation of Smad2 and ERK in total lung. However, hyperphosphorylation of neither Smad2 nor of ERK1/2 was observed in isolated $T \beta R I I^{N k x 2.1-c r e}$ alveolar type II cells (Figure 3).

A

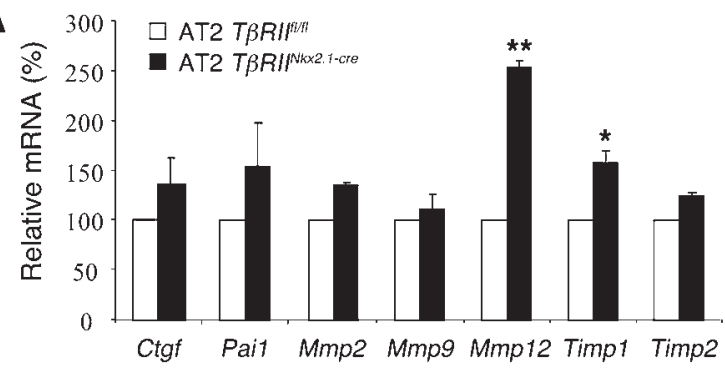

B

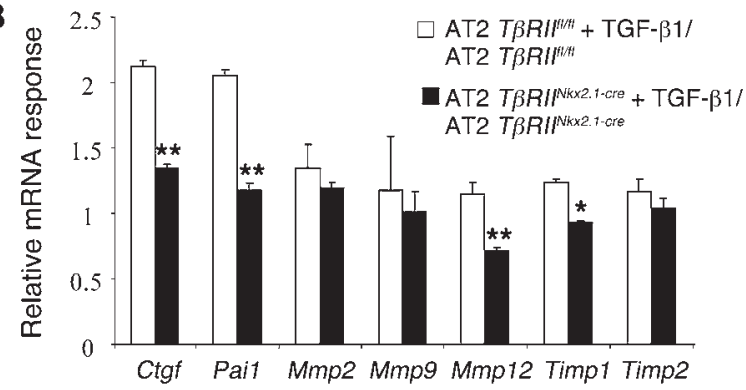


Thus, increased activation of the Smad 2 and ERK1/2 pathways, observed exclusively in total T $\beta R I I^{N k x 2.1-c r e}$ lungs, is likely of mesodermal origin, a cell type that is not a target of Nkx2.1-cre and in which the T $\beta R I I$ locus remains intact. This possibility was further validated by double immunodetection of $\mathrm{Nkx} 2.1$ and $\mathrm{p}-\mathrm{Smad} 2$ in lung tissue, demonstrating an increase in p-Smad2 in cells not labeled by the Nkx2.1 antibody (Supplemental Figure 2). Implicit in this observation is the interesting possibility that epitheliumspecific inactivation of T $\beta R I I$ may, by an as-yet-unknown epithelialmesenchymal crosstalk, elicit a (hyper?) compensatory mesenchymal response. Although the latter possibility requires further investigation, in a separate study, dermal fibroblast-specific deletion of $T \beta R I I$ interrupted mesenchymal-epithelial interactions and hence severely impeded re-epithelialization of skin wound repair (28).

In isolated T $\beta R I I^{N k x 2.1-c r e}$ alveolar type II cells, T $\beta$ RII protein was decreased by more than $70 \%$, the residual potentially reflecting either incomplete Nkx2.1-cre-driven recombination or contaminating mesenchyme, the latter being unlikely, as cell purity normally exceeded $90 \%$. In the mutant type II cells, steady-state levels of total Smad2 and Smad3 were unchanged (Figure 3). Whereas basal levels of p-Smad3 were nearly undetectable, Smad 2 was clearly phosphorylated in both control and T $T R I I^{N k x 2.1-c r e}$ type II cells, albeit at lower levels in the mutant cells. TGF- $\beta$ treatment elicited phosphorylation of Smad 2 and Smad 3 in both control and mutant type II cells, although the magnitude of response, particularly for Smad3, in mutant cells was blunted (Figure 3). Whether residual $\mathrm{T} \beta \mathrm{RII}$ in the mutant cells, due to incomplete Nkx2.1-cre recombination activity, accounted entirely for activation of $S \operatorname{mad} 2$ and $S m a d 3$ in response to TGF- $\beta$ is unlikely but remains a possibility. In contrast to the present findings, Smad2 phosphorylation in response to TGF- $\beta$ treatment was entirely absent in T $\beta R I I$-deleted dermal fibroblast explants (28), raising the alternate possibility that the mechanisms of TGF- $\beta$ signal transduction in the absence of T $\beta$ RII may be different in cells of endodermal versus mesodermal origin.

Surprisingly, total collagen content under steady-state conditions was greater in mutant lungs compared with controls. Real-time PCR of mRNA for ECM proteins showed significantly increased Col3a1 and fibronectin in T $\beta R I I^{N k x 2.1-c r e}$ lungs (Figure 4). Yet examination of $T \beta R I I^{N k x 2.1-c r e}$ lungs in mice at 8 weeks of age revealed no signs of fibrosis, indicating that increased collagen in the mutant lungs does not cause progressive fibrosis and as discussed above is associated with airspace enlargement and emphysematous changes. Similarly, mice carrying epithelium-specific deletion of $\alpha 3 \beta 1$ integrin have increased baseline collagen IV but are protected against bleomycin-induced fibrosis (6). Also, in contrast to Smad3 $3^{-/}$mice in which alveolar destruction is progressive (13), we found no evidence of progressive emphysema in T $T R I^{N k x 2.1-c r e}$ mice after 11 months of age (data not shown). This difference may relate to baseline developmental abnormalities of insufficient lung alveolization observed in Smad3 $3^{-/-}$animals (29), which although mild, might presumably predispose to a more severe adult phenotype. A possible explanation for the increased basal collagen and ECM content in T $\beta R I I^{\text {Nkx2.1-cre }}$ lungs may be the increased activation of both the Smad (p-Smad2) and the non-Smad ( $\mathrm{p}$-ERK) TGF- $\beta$ signal transduction pathways in the mesenchyme of the mutant lungs (Figure 2 and Supplemental Figure 2). Stimulation of collagen I synthesis by TGF- $\beta$ has been found to require activation of ERK1/2 (30).

$T \beta R I I^{N k x 2.1-c r e}$ mice exhibited a remarkable degree of resistance to TGF- $\beta$-mediated bleomycin lung injury relative to the $T \beta R I I^{f / f l}$ and wild-type controls. First, i.t. administered bleomycin, which result- ed in nearly $100 \%$ lethality in the control mice, was well tolerated without mortality in $T \beta R I I^{N k x 2.1-c r e}$ mice (Figure 5). This is strong physiologic evidence that abrogation of epithelial T $\beta$ RII function provides effective protection against bleomycin lung injury and the consequent pulmonary fibrosis. Second, a less injurious bleomycin regimen (i.n. delivery) caused only minor fibrotic lesions in the $T \beta R I I^{N k x 2.1-c r e}$ lungs, compared with $T \beta R I I^{f / f l}$ controls (Figure 6). From a physiological standpoint, lung function in the mutant mice was remarkably preserved, reflected in significantly lower epithelial permeability and better compliance measures compared with controls. These findings are consistent with the previous study by Pittet et al. (31) implicating TGF- $\beta$ in bleomycin-induced increases in epithelial permeability and demonstrating that inhibition of TGF- $\beta$ signaling protected mice from pulmonary edema due to bleomycin. Our results confirm and extend the previous findings of Pittet et al. by identifying T $\beta$ RII as the receptor mediator of the impact of TGF- $\beta$ on epithelial permeability.

Although the precise mechanism underlying the protective effects of epithelium-specific deletion of T $\beta R I I$ remains to be determined, the following may provide a plausible explanation. First, the absence of Smad3 has been linked to protection against bleomycin. In $T \beta R I I^{N k x 2.1-c r e ~ l u n g s, ~ a c t i v a t i o n ~ o f ~ t h i s ~ p a t h w a y ~ i s ~}$ clearly blunted (Figure 2). TGF- $\beta$ is a known mediator of cellular apoptosis (32) and EMT (7), both of which feature prominently in the epithelial abnormalities and defective repair that characterize bleomycin-induced pulmonary fibrosis (33). Reduced signaling via Smad3 in the epithelium may result in improved epithelial cell survival and/or inhibition of EMT. A possible role for the epithelium in pulmonary fibrosis was originally suggested by the observation that epithelial injury and blunted repair in mouse lung explants was sufficient to promote fibrosis in the absence of inflammation, and that the presence of an intact epithelium suppressed fibroblast proliferation and matrix deposition $(2,34)$. Epithelial injury of unknown cause is postulated to play a central role in disease pathogenesis through release of mediators that lead to fibroblast activation and matrix deposition analogous to abnormal wound healing. In addition, recent studies indicating that alveolar epithelial cells undergo EMT in response to TGF- $\beta$ in vitro (7) and in vivo (6) and that colocalization of epithelial and mesenchymal markers in hyperplastic type II cells in IPF lung tissue suggest that alveolar epithelial cells may also contribute directly to fibroblast accumulation through EMT. Although the issue of EMT in vivo was not specifically addressed in the present study, preliminary work indicates that isolated $T \beta R I I^{N k x 2.1-c r e}$ type II cells are resistant to TGF- $\beta$-induced EMT in vitro (data not shown). Within the fibrotic foci, TUNEL assays indicated an increase in apoptosis in cells that were further found to have fibroblastic characteristics (data not shown). These findings support the notion that improved epithelial survival associated with epithelium-specific deletion of T $\beta$ RII in mutant mice may limit fibrogenesis by opposing fibroblast proliferation/survival and increasing fibroblast apoptosis. Consistent with this possibility, $\mathrm{Smad3}^{-/-}$animals also showed increased resistance to radiationinduced cell death (35). Increased p-Smad 2 may also explain the observed relative resistance to bleomycin in T $\beta R I I^{\text {Nkx2.1-cre lungs, as }}$ it has been shown that deletion of Smad2 promotes fibrosis (36). The precise mechanism remains entirely unknown.

A third possible mechanism for the observed protection against bleomycin-induced fibrosis in T $\beta R I I^{\text {Nkx2.1-cre }}$ mice is based on the analysis of the ECM, metalloproteinases, and their inhibitors. 
Metalloproteinases are thought to mediate tissue damage and matrix remodeling (37-39). The steady-state levels of both Mmp12 and Timp1 were increased in T $\beta R I I^{N k x 2.1-c r e ~}$ lungs (Figure 4). We propose a "homeostatic balance" model to explain the observed protection against bleomycin in the mutant lungs. This model is based on the principle that the key factor in the etiology of fibrosis may not necessarily be the absolute level of each component, but rather the balance among ECM, metalloproteinases, and their inhibitors. In the mutant lungs, steady-state levels of ECM, metalloproteinases, and their inhibitors were all increased, therefore constituting a homeostatic balance. This balance also exists in the control lungs, albeit at lower levels. The key difference between the control and the mutant lungs is the manner in which each responded to bleomycin injury. In the control, we observed a robust increase, by several fold, in fibronectin, metalloproteinase, and Timp levels, creating a non-homeostatic environment. In comparison, the response in the mutant lungs was minimal. Thus, the overall "balance" of ECM, metalloproteinases, and Timps in the mutant versus control animals may create an environment less likely to promote excessive matrix deposition and fibrosis. It should be noted that the function of Mmps is complex, as these molecules may have additional effects besides matrix degradation and remodeling, including a role in release of growth factors from cell membranes, cleavage of growth factor receptors from cell surface, and activation of other Mmps.

Emphysema and fibrosis have been typically regarded as different disorders, although both may represent context-dependent host responses to inflammation/injury. However, the mechanisms that mediate these differing host responses are poorly understood, particularly since matrix-associated genes and collagen expression may be altered in both disorders. Signaling through Smad3 appears to be absolutely required for progression to fibrosis (13). As mentioned above, inactivation of signaling via Smad3 is protective against fibrosis but has been associated in a number of studies including the current one with the development of an emphysema phenotype (13). In the absence of Smad3, progression to fibrosis is prevented, and there is a smaller increase in protease inhibitors, suggesting that even if matrix were deposited, it would be readily digested (13). In the current study, although there was an increase in baseline Mmp12 and following injury, there was also a marked increase in baseline Timp1, suggesting a mechanism for increased collagen III at baseline. However, collagen deposition was not progressive, and animals developed emphysema, suggesting that in an environment where Smad3 activation is reduced, over time, the balance of MMPs versus TIMPs favors matrix degradation. This suggests that while inhibition of Smad3 signaling may be protective against fibrosis, some level of Smad3 signaling may be necessary to prevent matrix degradation by Mmps in the course of normal cellular maintenance and repair. However, in response to injury, inhibition of Smad3 signaling appears to in fact prevent excess matrix accumulation, perhaps by limiting induction of TIMPs and creating an environment that on balance favors matrix degradation. An interesting study by Niewoehner et al. demonstrated that the response to $\mathrm{CdCl} 2$ injury, i.e., fibrosis versus emphysema differed depending on whether the capacity to synthesize connective tissue was prevented (40). These findings suggest that while $\mathrm{Smad} 3$ is required for progression to fibrosis, the precise balance of matrix degrading versus protease inhibitory enzymes as well as levels of matrix-associated genes expressed may determine the ultimate outcome and response to injury.
In summary, the results demonstrate for the first time to our knowledge that epithelial TGF- $\beta$ signaling via T $\beta$ RI contributes to pulmonary fibrosis and identify this receptor as a target for potential rational therapeutic strategies.

\section{Methods}

Animals. Nkx2.1-cre, Rosa26-lacZ, and T $\beta R I^{f / f l}$ mice have been previously described $(17,41-43)$ and were maintained on the C57BL/ 6 genetic background. To generate $T \beta R I I^{f / f l} ; N k x 2.1$-cre $\left(T \beta R I I^{N k x 2.1-c r e}\right)$ embryos, we crossed $T \beta R I I^{f /+} ; N k \times 2.1$-cre mice with $T \beta R I I^{f / f l}$ mice. Nkx2.1-cre;Rosa26-lacZ mice were generated by breeding $N k x 2.1$-cre and Rosa26-lacZ mice.

Detection of $\beta$-galactosidase activity. $\beta$-Galactosidase (LacZ) activity in embryonic lungs was determined by whole mount $\mathrm{X}$-gal staining as described previously (44), and lungs were then sectioned with a cryomicrotome. Lungs of postnatal day $7(\mathrm{Pn} 7)$ mice were perfused and fixed in $4 \%$ PFA for 30 minutes at $4^{\circ} \mathrm{C}$. Lungs were embedded in OCT and sectioned by cryomicrotome, and frozen sections were washed with PBS and stained for LacZ activity.

Bleomycin injury. Mice (6-8 weeks old) were anesthetized with ketamine and xylazine and administered i.t. $(1.3-2 \mathrm{U} / \mathrm{kg})$ or i.n. $(6 \mathrm{U} / \mathrm{kg})$ injections of bleomycin (bleomycin injectable, treatment grade) or sterile saline. Mice were sacrificed for analysis 14 and 21 days after administration of bleomycin. Animal usage and bleomycin protocols for these studies were approved by the Institutional Animal Care and Use Committee of the USC Keck School of Medicine.

Morphological analysis. Adult lungs were perfused and fixed in 4\% PFA and processed into serial paraffin sections using routine procedures. $\mathrm{H} \& \mathrm{E}$ staining was performed on $5-\mu \mathrm{m}$ sections. Quantitative morphological analyses were performed using 3 morphometric parameters: mean linear intercept, mean size, and mean number of alveolar spaces. From each lung specimen, mean linear intercept was measured on 5 representative slides of each sample as previously described (45). Mean size and mean number of alveolar spaces were calculated with the same slides by using ImageJ software provided by the NIH.

Immunohistochemistry. Samples were fixed in 4\% PFA and processed into serial paraffin sections using routine procedures. Tissue sections $(5 \mu \mathrm{m})$ were deparaffinized and rehydrated in xylene, heated in $10 \mathrm{mM}$ citrate buffer ( $\mathrm{pH}$ 6.0), treated with $1 \% \mathrm{H}_{2} \mathrm{O}_{2}$ in methanol for 10 minutes, and blocked with $5 \%$ normal serum. For immunohistochemistry, sections were incubated with primary antibodies at $4{ }^{\circ} \mathrm{C}$ overnight. After incubation with secondary antibody for 1 hour at room temperature, an avidin-biotin complex method was used to detect bound antibodies (Invitrogen).

For immunofluorescence staining, FITC-conjugated horse anti-mouse, FITC-conjugated donkey anti-rabbit, FITC-conjugated goat anti-hamster, Cy3-conjugated goat anti-mouse, and Cy3-conjugated donkey anti-rabbit antibodies (Vector Laboratories) were applied to sections for 1 hour at room temperature. Sections were preserved in VECTASHELD mounting medium with DAPI to visualize nuclei. Primary antibodies used were: rabbit anti-Nkx2.1, rabbit anti-SP-C and rabbit anti-SP-B (Seven Hills Bioreagents), rabbit anti-T $\beta$ RII (Abcam), mouse anti- $\alpha$-tubulin (Invitrogen), goat anti-CC10 (Santa Cruz Biotechnology Inc.), and hamster anti-T1- $\alpha$ (obtained from the Developmental Studies Hybridoma Bank).

TUNEL assay. Apoptotic cells were detected by using TUNEL detection kit (In Situ Cell Death Detection Kit, Roche Applied Science). Briefly, tissue sections were deparaffinized, rehydrated, and washed with distilleddeionized water. After treatment with proteinase $\mathrm{K}$, fragmented DNA was labeled with fluorescein-dUTP, using terminal transferase. Slides were mounted with DAPI containing Vectashield. Sections were analyzed using a fluorescence microscope (Carl Zeiss Meditec) and a fluorescence detection system (OPTI-QUIP). The apoptotic percentage was obtained by manual counting of TUNEL ${ }^{+}$cells in groups of 4,000 or more cells. 
Western blot analysis. Lungs were isolated and homogenized, followed by brief sonication for 30 seconds in $2 \%$ SDS lysis buffer containing protease and phosphatase inhibitors. Lysates were then centrifuged at $15,000 \mathrm{~g}$ for 10 minutes, and supernatants were saved at $-80^{\circ} \mathrm{C}$. Equal amounts of protein lysate were resolved by SDS-PAGE and blotted onto Immuno-Blot polyvinylidene fluoride membranes (Bio-Rad). Membranes were incubated with primary antibodies for 1 hour after blocking with $5 \%$ nonfat milk in $20 \mathrm{mM}$ Tris ( $\mathrm{pH} 7.5$ ), $0.5 \mathrm{M} \mathrm{NaCl}$, and $0.01 \%$ Tween 20 for 1 hour. Blots were then incubated with HRP-linked anti-IgG conjugates for 1 hour at room temperature. Proteins were visualized by enhanced chemiluminescence (Amersham Biosciences). Primary antibodies used were: $\alpha$-tubulin (Invitrogen), Smad2, Smad3, p-Smad2, p-Smad3, ERK and p-ERK (Cell Signaling Technology), FSP1 (Vector Laboratories), $\alpha$-SMA (Sigma-Aldrich), and lamin A/C (Santa Cruz Biotechnology Inc.).

RNA extraction and real-time PCR. Total RNA was extracted from lungs or cells using Trizol (Invitrogen). cDNA was synthesized from $2 \mu \mathrm{g}$ total RNA using Superscript First-Strand Synthesis System kit (Invitrogen). Quantification of the selected genes by quantitative PCR (qPCR) was performed using a LightCycler (Roche Diagnostics), as previously described (46). Sequences of the primers were as follows: mouse Ctgf: 5'-TGACCTGGAGGAAAACATTAAGA-3' (forward), 5'-AGCCCTGTATGTCTTCACACTG-3' (reverse); mouse Pail: 5'-CTCCTCATCCTGCCTAAGTT-3' (forward), 5'-GCCAGGGTTGCACTAAACAT-3' (reverse); mouse Mmp2: 5'-TAACCTGGATGCCGTCGT-3' (forward), 5'-TTCAGGTAATAAGCACCCTTGAA-3' (reverse); mouse Mmp9: 5'-CTACATAGACGGCATCCAG-3' (forward), 5'-CTGTCGGCTGTGGTTCAGT-3' (reverse); mouse Mmp12: 5'-TTGTGGATAAACACTACTGGAGGT-3' (forward), 5'-AAATCAGCTTGGGGTAAGCA-3' (reverse); mouse Timp1: 5'-GCATTGAGCTTTCTCAAAGACC-3' (forward), 5'-AGGGATAGATAAACAGGGAAACACT-3' (reverse); mouse Timp2: 5'-AGGTACCAGATGGGCTGTGA-3' (forward), 5'-GTCCATCCAGAGGCACTCAT-3' (reverse); mouse $\beta$-actin: 5'-CCAACCGTGAAAAGATGACC-3' (forward), 5'-CCAGAGGCATACAGGGACAG-3' (reverse); mouse Col1a1: 5'-CTGCTGGCAAAGATGGAGA-3' (forward), 5'-ACCAGGAAGACCCTGGAATC-3' (reverse); mouse Col3a1: 5'-CAAATGGCATCCCAGGAG-3' (forward), 5'-CATCTCGGCCAGGTTCTC-3' (reverse); mouse Col4a1: 5'-AGCTGCTAAAGGTGACATTCCT-3' (forward), 5'-GGAGGCCCAGGTACTCCT-3' (reverse); mouse Fn1: 5'-TGCACGATGATATGGAGAGC-3' (forward), 5'-TGGGTGTCACCTGACTGAAC-3' (reverse); mouse $\alpha$-SMA: $5^{\prime}$-TGACGCTGAAGTATCCGATAGA-3' (forward), 5'-CGAAGCTCGTTATAGAAAGAGTGG-3' (reverse).

Mouse alveolar type II cell isolation and partial purification. Mouse alveolar type II cells were isolated from either floxed or $T \beta R I I^{N k x 2.1-c r e}$ mice as previously described (47). Briefly, the animals were anesthetized and the lungs perfused with PBS. Dispase, followed by $0.5 \mathrm{ml}$ of $1 \%$ lowmelting-point agarose, was injected into the trachea. Lungs were excised and incubated for 45 minutes in dispase at room temperature. Lungs were dissected into wash medium and chopped. The resulting crude cell mixture was incubated for 10 minutes at room temperature, followed by passage through a series of Nitex filters and centrifugation at $300 \mathrm{~g}$ for 10 minutes. Macrophages and other cells were negatively selected by using biotin-conjugated antibodies and subsequent coupling with streptavidin magnetic beads. Cells were plated onto IgG-coated plates, and the unattached alveolar epithelial cells ( $\geq 90 \%$ purity) were collected and plated $\left(700,000\right.$ cells $\left./ \mathrm{cm}^{2}\right)$ onto polycarbonate filters $(0.4-\mu \mathrm{m}$ pore size, $1.1 \mathrm{~cm}^{2}$; Corning Costar) coated with laminin-5 $(1 \mu \mathrm{g} / \mathrm{ml})$, with media containing cis-hydroxyproline $(100 \mu \mathrm{g} / \mathrm{ml})$ for further experiments.

Sircol assay. The Sircol collagen assay (Biocolor) was performed following the manufacturer's instructions. Briefly, $1 \mathrm{ml}$ of Sirius red reagent was added to each lung homogenate $(50 \mu \mathrm{l})$ and mixed for 30 minutes. The collagen-dye complex was precipitated by centrifugation at $10,000 \mathrm{~g}$ for 10 minutes, and the pellet was dissolved in the alkali reagent supplied. Finally, absorbance of samples was measured at $540 \mathrm{~nm}$. Collagen concentration in the bleomycin samples (expressed as $\mu \mathrm{g} / \mathrm{lung}$ ) was normalized against littermate control saline samples.

Compliance measurements. Lung function was assessed by invasive measurement of airway compliance (Buxco FinePointe Systems, Buxco Electronics), in which anesthetized and tracheostomized mice were mechanically ventilated using a modified version of a described method (48). Mice treated with either bleomycin or saline for 14 days were ventilated in volume-driven mode with a positive end-expiratory pressure (PEEP) of $0 \mathrm{mmHg}$. Before measurement of lung compliance, chambers were calibrated. Respiration rate was set to $140 / \mathrm{min}$, and ventilation pressure was recorded while inflating the lung at a tidal volume of $350 \mu$. We continuously computed dynamic compliance by fitting flow, volume, and pressure to an equation of motion. Ventilator compliance is expressed as $\mathrm{kPa} / \mathrm{ml}$ and corrected for the saline controls.

Lung permeability. Total protein concentration $(\mathrm{mg} / \mathrm{ml})$ from bronchoalveolar lavage (BAL) obtained from both saline- and bleomycin-treated mice was measured by DC protein assay (Bio-Rad) according to the manufacturer's protocol.

Statistics. For qPCR and Western blot analysis, each experiment was repeated with the samples obtained from at least 2 different lungs or cell preparations. All results are expressed as mean \pm SEM. The significance of differences between 2 sample means was determined by 2 -tailed Student's $t$ tests. A $P$ value less than 0.05 was considered significant.

\section{Acknowledgments}

This work was supported by grants HL095349 (to P. Minoo) and HL089445 (to Z. Borok) from the National Heart, Lung, and Blood Institute/NIH and by the Hastings Foundation. Parviz Minoo is Hastings Professor of Pediatrics. Zea Borok is Ralph Edgington Chair in Medicine.

Received for publication December 18, 2009, and accepted in revised form October 13, 2010.

Address correspondence to: Parviz Minoo, Department of Pediatrics, Women's and Children's Hospital, LAC+USC Medical Center, 1801 East Marengo Street, Room 1G1, Los Angeles, California 90033, USA. Phone: 323.226.4340; Fax: 213.236.5049;E-mail: minoo@usc.edu. Or to: Zea Borok, Will Rogers Institute Pulmonary Research Center, Division of Pulmonary and Critical Care Medicine, Keck School of Medicine of the University of Southern California, IRD 723, M/C 9520, Los Angeles, California 90089-9520, USA. Phone: 323.226.7923; Fax: 323.226.2738; E-mail: zborok@usc.edu.
1. Lecart $\mathrm{C}$, et al. Bioactive transforming growth factor-beta in the lungs of extremely low birthweight neonates predicts the need for home oxygen supplementation. Biol Neonate. 2000;77(4):217-223.

2. Adamson IY, Hedgecock C, Bowden DH. Epithe-

lial cell-fibroblast interactions in lung injury and repair. Am J Pathol. 1990;137(2):385-392.

3. Adamson IY, King GM, Bowden DH. Collagen breakdown during acute lung injury. Thorax.
1988;43(7):562-568.

4. Hagimoto N, Kuwano K, Nomoto Y, Kunitake R, Hara N. Apoptosis and expression of Fas/Fas ligand mRNA in bleomycin-induced pulmonary fibrosis in mice. Am J Respir Cell Mol Biol. 1997;16(1):91-101.

5. Selman M, King TE, Pardo A. Idiopathic pulmonary fibrosis: prevailing and evolving hypotheses about its pathogenesis and implications for therapy. Ann Intern Med. 2001;134(2):136-151.
6. Kim KK, et al. Alveolar epithelial cell mesenchymal transition develops in vivo during pulmonary fibrosis and is regulated by the extracellular matrix. Proc Natl Acad Sci U S A. 2006;103(35):13180-13185.

7. Willis BC, et al. Induction of epithelialmesenchymal transition in alveolar epithelial cells by transforming growth factor-beta1: potential role in idiopathic pulmonary fibrosis. Am J Pathol. 2005;166(5):1321-1332. 
8. Massague J. TGF-beta signal transduction. Annu Rev Biochem. 1998;67:753-791.

9. Heldin CH, Miyazono K, ten Dijke P. TGF-beta signalling from cell membrane to nucleus through SMAD proteins. Nature. 1997;390(6659):465-471.

10. Wrana JL. Crossing Smads. Sci STKE. 2000; 2000(23):re1.

11. Sanford LP, et al. TGFbeta2 knockout mice have multiple developmental defects that are non-overlapping with other TGFbeta knockout phenotypes. Development. 1997;124(13):2659-2670.

12. Kaartinen $V$, et al. Abnormal lung development and cleft palate in mice lacking TGF-beta 3 indicates defects of epithelial-mesenchymal interaction. Nat Genet. 1995;11(4):415-421.

13. Bonniaud P, et al. Smad3 null mice develop airspace enlargement and are resistant to TGF-betamediated pulmonary fibrosis. J Immunol. 2004; 173(3):2099-2108

14. Chu GC, Dunn NR, Anderson DC, Oxburgh L, Robertson EJ. Differential requirements for Smad4 in TGFbeta-dependent patterning of the early mouse embryo. Development. 2004;131(15):3501-3512.

15. Oshima M, Oshima H, Taketo MM. TGF-beta receptor type II deficiency results in defects of yolk sac hematopoiesis and vasculogenesis. Dev Biol. 1996;179(1):297-302.

16. Li M, et al. Mesodermal deletion of transforming growth factor-beta receptor II disrupts lung epithelial morphogenesis: cross-talk between TGFbeta and Sonic hedgehog pathways. J Biol Chem. 2008;283(52):36257-36264

17. Xu Q, Tam M, Anderson SA. Fate mapping Nkx2.1lineage cells in the mouse telencephalon. J Comp Neurol. 2008;506(1):16-29.

18. Tiozzo C, et al. Deletion of pten expands lung epithelial progenitor pools and confers resistance to airway injury. Am J Respir Crit Care Med. 2009; 180(8):701-712.

19. Sime PJ, Xing Z, Graham FL, Csaky KG, Gauldie J. Adenovector-mediated gene transfer of active transforming growth factor-beta1 induces prolonged severe fibrosis in rat lung. J Clin Invest. 1997; 100(4):768-776.

20. Willis BC, Borok Z. TGF-beta-induced EMT: mechanisms and implications for fibrotic lung disease. $A m J$ Physiol Lung Cell Mol Physiol. 2007;293(3):L525-L534.

21. Lawson WE, et al. Characterization of fibroblast- specific protein 1 in pulmonary fibrosis. Am J Respir Crit Care Med. 2005;171(8):899-907.

22. Liu T, et al. Lack of MK2 inhibits myofibroblast formation and exacerbates pulmonary fibrosis. $A m$ J Respir Cell Mol Biol. 2007;37(5):507-517.

23. Matute-Bello G, et al. Essential role of MMP-12 in Fas-induced lung fibrosis. Am J Respir Cell Mol Biol. 2007;37(2):210-221.

24. Kang HR, Cho SJ, Lee CG, Homer RJ, Elias JA Transforming growth factor (TGF)-beta1 stimulates pulmonary fibrosis and inflammation via a Bax-dependent, bid-activated pathway that involves matrix metalloproteinase-12. J Biol Chem. 2007;282(10):7723-7732.

25. Feinberg MW, et al. Transforming growth factor-beta 1 inhibits cytokine-mediated induction of human metalloelastase in macrophages. J Biol Chem. 2000;275(33):25766-25773.

26. Hautamaki RD, Kobayashi DK, Senior RM, Shapiro SD. Requirement for macrophage elastase for cigarette smoke-induced emphysema in mice. Science. 1997;277(5334):2002-2004.

27. Churg A, Wang R, Wang X, Onnervik PO, Thim K, Wright JL. Effect of an MMP-9/MMP-12 inhibitor on smoke-induced emphysema and airway remodelling in guinea pigs. Thorax. 2007;62(8):706-713.

28. Denton CP, et al. Inducible lineage-specific deletion of TbetaRII in fibroblasts defines a pivotal regulatory role during adult skin wound healing. J Invest Dermatol. 2009;129(1):194-204.

29. Chen $\mathrm{H}$, et al. Abnormal mouse lung alveolarization caused by Smad3 deficiency is a developmental antecedent of centrilobular emphysema. Am J Physiol Lung Cell Mol Pbysiol. 2005;288(4):L683-691.

30. Mishra R, Zhu L, Eckert RL, Simonson MS. TGFbeta-regulated collagen type I accumulation: role of Src-based signals. Am J Physiol Cell Physiol. 2007; 292(4):C1361-1369.

31. Pittet JF, et al. TGF-beta is a critical mediator of acute lung injury. J Clin Invest. 2001;107(12):1537-1544.

32. Budinger GR, et al. Proapoptotic Bid is required for pulmonary fibrosis. Proc Natl Acad Sci U S A. 2006;103(12):4604-4609.

33. Kim KK, et al. Epithelial cell alpha3beta1 integrin links beta-catenin and Smad signaling to promote myofibroblast formation and pulmonary fibrosis. J Clin Invest. 2009;119(1):213-224.

34. Adamson IY, Young L, Bowden DH. Relation- ship of alveolar epithelial injury and repair to the induction of pulmonary fibrosis. Am J Pathol. 1988;130(2):377-383.

35. Flanders KC, et al. Mice lacking Smad 3 are protected against cutaneous injury induced by ionizing radiation. Am J Pathol. 2002;160(3):1057-1068.

36. Ju W, et al. Deletion of Smad2 in mouse liver reveals novel functions in hepatocyte growth and differentiation. Mol Cell Biol. 2006;26(2):654-667.

37. Page-McCaw A, Ewald AJ, Werb Z. Matrix metalloproteinases and the regulation of tissue remodelling. Nat Rev Mol Cell Biol. 2007;8(3):221-233.

38. Atkinson JJ, Senior RM. Matrix metalloproteinase-9 in lung remodeling. Am J Respir Cell Mol Biol. 2003;28(1):12-24.

39. Corbel M, Boichot E, Lagente V. Role of gelatinases MMP-2 and MMP-9 in tissue remodeling following acute lung injury. Braz J Med Biol Res. 2000; 33(7):749-754.

40. Niewoehner DE, Hoidal JR. Lung fibrosis and emphysema: divergent responses to a common injury? Science. 1982;217(4557):359-360.

41. Soriano P. Generalized lacZ expression with the ROSA26 Cre reporter strain. Nat Genet. 1999; 21(1):70-71.

42. Chytil A, Magnuson MA, Wright CV, Moses HL. Conditional inactivation of the TGF-beta type II receptor using Cre:Lox. Genesis. 2002;32(2):73-75.

43. Xing Y, et al. Mechanisms of TGFbeta inhibition of LUNG endodermal morphogenesis: the role of TbetaRII, Smads, Nkx2.1 and Pten. Dev Biol. 2008;320(2):340-350.

44. Pan $\mathrm{Q}$, et al. In vivo characterization of the $\mathrm{Nkx} 2.1$ promoter/enhancer elements in transgenic mice. Gene. 2004;331:73-82.

45. Robbesom AA, et al. Morphological quantification of emphysema in small human lung specimens: comparison of methods and relation with clinical data. Mod Pathol. 2003;16(1):1-7.

46. Li C, et al. Wnt5a regulates Shh and Fgf10 signaling during lung development. Dev Biol. 2005; 287(1):86-97.

47. Demaio L, et al. Characterization of mouse alveolar epithelial cell monolayers. Am J Pbysiol Lung Cell Mol Physiol. 2009;296(6):L1051-L1058.

48. Martin TR, Gerard NP, Galli SJ, Drazen JM. Pulmonary responses to bronchoconstrictor agonists in the mouse. J Appl Physiol. 1988;64(6):2318-2323. 